\title{
Effects of airway calibre on lung delivery of nebulised salbutamol
}

\author{
B J Lipworth, D J Clark
}

\begin{abstract}
Background - A study was undertaken to test the hypothesis that airway calibre may alter lung deposition and therefore lung bioavailability of inhaled drugs as a result of narrowed airways reducing peripheral drug delivery. This was evaluated using the early lung absorption profile of salbutamol over the first 30 minutes after inhalation. Methods - Three groups were compared: (1) 10 normal subjects with mean forced expiratory volume in one second $\left(\mathrm{FEV}_{1}\right)$ $109.5 \%$ predicted and mid forced expiratory flow $\left(\mathrm{FEF}_{25-75}\right) 103.0 \%$, (2) 10 mild asthmatic patients with $F E V_{1} 102.0 \%$ and $\mathrm{FEF}_{25-75} 82.6 \%$, and (3) 10 severe asthmatic patients with $\mathrm{FEV}_{1} 49.2 \%$ and $\mathrm{FEF}_{25-75}$ $27.5 \%$ predicted. Each subject had one study visit where a single dose of nebulised salbutamol was given $(40 \mu \mathrm{g} / \mathrm{kg})$ via a Ventstream nebuliser with mouthpiece followed by mouth rinsing. Plasma salbutamol levels were measured at five, 10 , 20 , and 30 minutes after the end of nebulisation with calculation of maximal (Cmax) and average (Cav) concentration over 0-30 minutes. Systemic $\beta_{2}$ responses (plasma potassium, tremor and heart rate) and airway responses $\left(\mathrm{FEV}_{1}, \mathbf{F E F}_{25-75}\right)$ were measured before and 30 minutes after nebulisation.
\end{abstract}

Results - For Cav over 0-30 minutes the severe asthmatic patients had a lower plasma salbutamol concentration $(1.31 \mathrm{ng} /$ ml) than either the normal subjects $(2.40 \mathrm{ng} / \mathrm{ml})$ or those with mild asthma ( $2.45 \mathrm{ng} / \mathrm{ml})$ : normal subjects versus severe asthmatics $95 \%$ CI 0.30 to 1.88 , mild versus severe asthmatics $95 \%$ CI 0.07 to 2.21. Airway responses as delta $\mathbf{F E F}_{25-75}$ were lower in the severe asthmatic subjects $(0.301 / s)$ than in either the normal subjects $(0.691 / \mathrm{s})$ or those with mild asthma (0.741/s): normal subjects versus severe asthmatic subjects $95 \%$ CI 0.09 to 0.88 , mild versus severe asthmatics $95 \%$ CI 0.04 to 0.93 . Values for delta $\log$ tremor also showed attenuated responses in those with severe asthma $\left(1.22 \mathrm{mg}^{2} / \mathrm{s}\right)$ compared with normal subjects $\left(2.00 \mathrm{mg}^{2} / \mathrm{s}\right)$ or those with mild asthma $\left(2.02 \mathrm{mg}^{2} / \mathrm{s}\right)$ : normal subjects versus those with severe asthma $95 \%$ CI -0.02 to 3.30 , mild versus severe asthmatics $95 \%$ CI 0.02 to 3.30 .

Conclusions - These results show that baseline airway calibre significantly alters the early lung absorption profile of salbutamol in patients with severe asthma. This may have implications in terms of optimising dose and delivery of inhaled $\beta_{2}$ agonists in these patients.

(Thorax 1997;52:1036-1039)

Keywords: nebulised salbutamol, lung delivery, airway calibre.

From first principles it may be expected that reduced small airway calibre could alter lung deposition and therefore lung bioavailability. However, there are currently few pharmacokinetic data available that specifically address this issue. Melchor et al have shown that airway calibre does appear to affect peripheral lung deposition in a radiolabelling study in normal and asthmatic subjects in which the peripheral lung deposition was significantly higher in the normal group. The same result - that is, a 1.5fold difference in lung deposition consequent upon an approximately twofold greater baseline forced expiratory volume in one second $\left(\mathrm{FEV}_{1}\right)$ in normal subjects - was seen with metered dose inhaler, large volume spacer, and Diskhaler delivery devices. Pavia et al also used radiolabelling techniques to establish that there was a direct relationship between peripheral deposition and baseline $\mathrm{FEV}_{1}$ in asthmatic patients. $^{2}$

Inhaled pharmacokinetics have been assessed using urinary excretion of sodium cromoglycate in patients with obstructive airway disease and normal controls. ${ }^{3}$ This revealed that patients with chronic bronchitis but not those with asthma had lower lung bioavailability of sodium cromoglycate than normal subjects. This in part may be explicable by the fact that the $\mathrm{FEV}_{1}$ was lowest in the bronchitic group. A more relevant clinical issue, however, is the effect of airway calibre on the lung delivery of $\beta_{2}$ agonists as reduced delivery could in theory influence the bronchodilator response in acute asthma. The only data with $\beta_{2}$ agonists of which we are aware is retrospective. The pharmacokinetic profile of $4 \mathrm{mg}$ of inhaled fenoterol from two studies using the same metered dose inhaler and protocol in normal and asthmatic subjects $\left(\mathrm{FEV}_{1} 56 \%\right.$ predicted) showed a twofold difference in peak plasma fenoterol concentration between the groups $(1.6 \mathrm{ng} / \mathrm{ml}$ in those with asthma and $3.1 \mathrm{ng} / \mathrm{ml}$ in normal subjects). ${ }^{45}$

In the current study we have therefore assessed prospectively the early lung absorption profile of salbutamol from a nebuliser in both mild and severe asthmatics and also in normal subjects. We have previously shown that the lung bioavailability for salbutamol may be quantified reproducibly by measuring the early lung absorption profile over the first 30 minutes 
Table 1 Salbutamol responses

\begin{tabular}{lccr}
\hline & Normals & Mild asthma & Severe asthma \\
\hline Cmax (ng/ml) & $2.87^{*}(0.26$ to 2.09$)$ & $2.88(-0.11$ to 2.47$)$ & 1.69 \\
Cav $(\mathrm{ng} / \mathrm{ml})$ & $2.40^{*}(0.30$ to 1.88$)$ & $2.45^{*}(0.07$ to 2.21$)$ & 1.31 \\
Delta $\mathrm{log}$ tremor $\left(\mathrm{mg}^{2} / \mathrm{s}\right)$ & $2.00(-0.02$ to 3.30$)$ & $2.02^{*}(0.02$ to 3.30$)$ & 1.22 \\
Delta heart rate $(\mathrm{beats} / \mathrm{min})$ & $10.9^{*}(0.2$ to 10.4$)$ & $12.0(-0.1$ to 12.9$)$ & 5.6 \\
Delta potassium $(\mathrm{mmol} / \mathrm{l})$ & $-0.17(-0.19$ to 0.14$)$ & $-0.22(-0.21$ to 0.07$)$ & -0.14 \\
Delta $\mathrm{FEF}_{25-75}(1 / \mathrm{s})$ & $0.69^{*}(0.09$ to 0.88$)$ & $0.74 *(0.04$ to 0.93$)$ & 0.30 \\
${\text { Delta } \mathrm{FEV}_{1}(\mathrm{l})}$ & $0.22(-0.18$ to 0.59$)$ & $0.42(-0.38$ to 0.39$)$ & 0.42 \\
\hline
\end{tabular}

Data are shown after administration of salbutamol for pharmacokinetic, airway and extrapulmonary $\beta_{2}$ adrenoceptor responses. Values are given as means for each group, as well as $95 \%$ CI for differences compared with subjects with severe asthma.

$* \mathrm{p}<0.05$ for mild asthmatic or normal subjects vs severe asthmatic subjects.

after inhalation ${ }^{6}$ producing a sensitive index of lung deposition. ${ }^{7-9}$ Indeed, the oral bioavailability of salbutamol amounts to less than $0.3 \%$ for the first 30 minutes after inhalation. ${ }^{10}$

\section{Methods}

\section{SUBJECTS}

Three groups were studied: (1) 10 normal $\mathrm{FEV}_{1} 109.5$ (8.2)\% predicted, mid forced expiratory flow $\left(\mathrm{FEF}_{25-75}\right) 103.0$ (14.9)\% predicted, (2) 10 patients with mild asthma aged 31.7 (8.7) years, $\mathrm{FEV}_{1} 102.0$ (8.0)\% predicted, $\mathrm{FEF}_{25-75} 82.6$ (17.6)\% predicted, and (3) 10 subjects of mean (SD) age 20.6 (1.0) years,

patients with severe asthma aged 52.9 (15.2) years with $\mathrm{FEV}_{1} 49.2$ (15.9)\% predicted, $\mathrm{FEF}_{25-75} 27.5$ (11.2)\% predicted. All subjects gave written informed consent, the study having been approved by the Tayside medical ethics committee.

PROTOCOL

The subjects each had one study visit. A single dose of nebulised salbutamol (Ventolin, Allen and Hanburys, Uxbridge, UK) was given with the dose being adjusted for body weight $(40 \mu \mathrm{g} /$ $\mathrm{kg}$ ) via a Ventstream nebuliser with mouthpiece (Medic-Aid, Pagham, UK) driven by com-
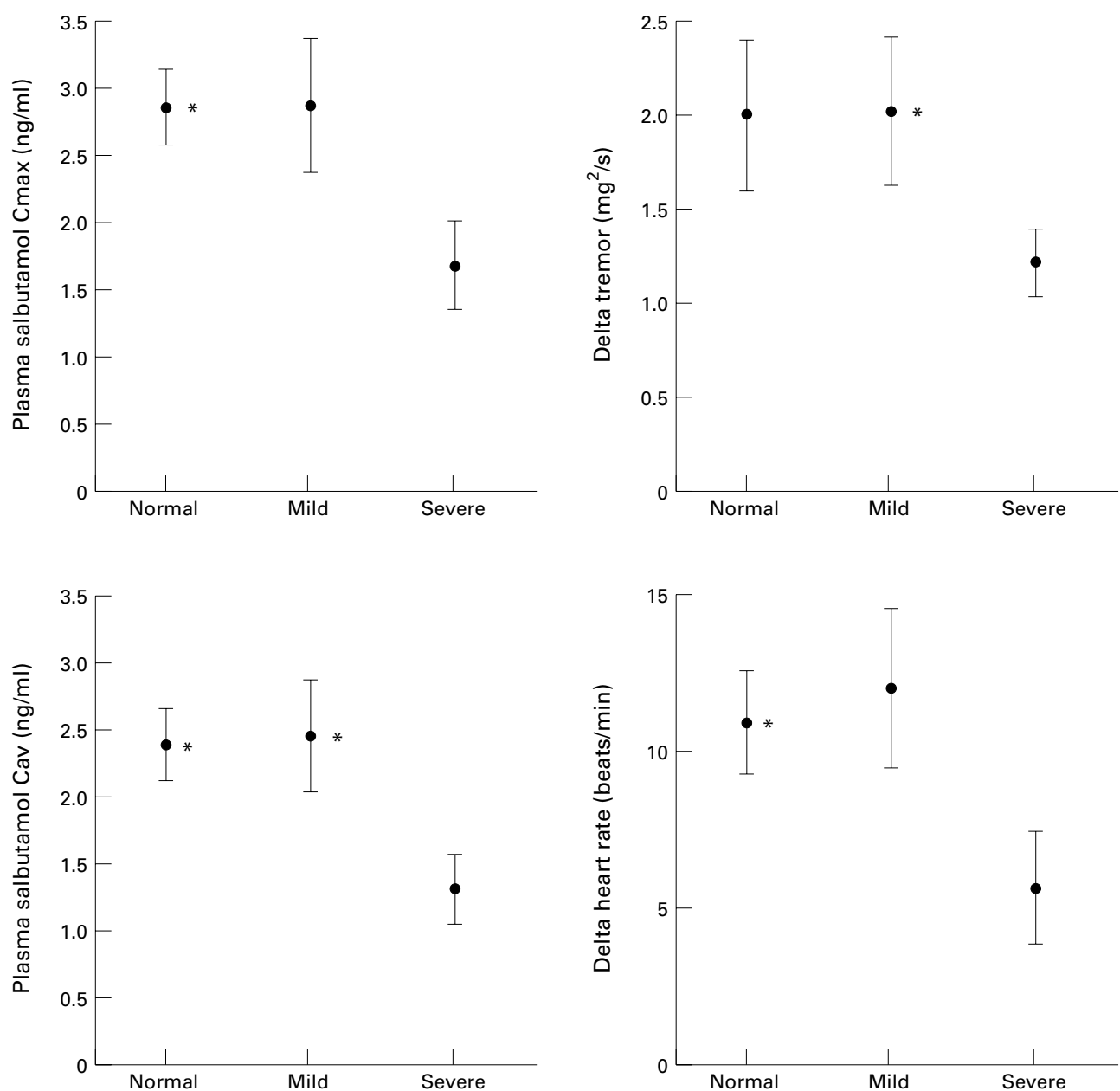

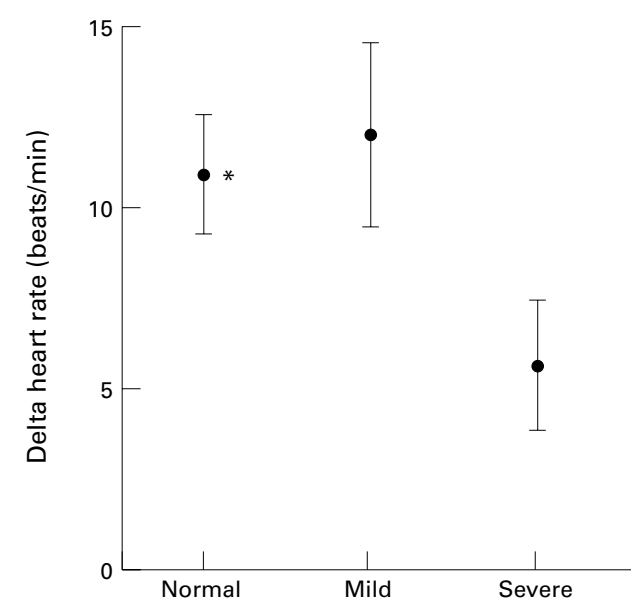

Figure 1 Mean (SE) values for plasma salbutamol peak (Cmax) and average (Cav) levels and for the increase in tremor and heart rate. ${ }^{*} p<0.05$ difference between the severe asthmatic group and either the normal subjects or those with mild asthma. 
pressed air at $8 \mathrm{l} / \mathrm{min}$. The mean (range) salbutamol dose (mg) was not significantly different between the groups: normal subjects 3.28 (2.86-3.88), mild asthmatics 3.13 (2.243.60), severe asthmatics 3.11 (2.54-3.84). Each dose of salbutamol was given in a total fill volume of $4 \mathrm{ml}$ made up with saline and nebulised to dryness over 8 minutes. Mouth rinsing was performed after completion of nebulisation in order to further obviate gastrointestinal absorption, even though the latter would be expected to be minimal.

Plasma salbutamol levels were measured at five, 10, 20, and 30 minutes after the end of nebulisation. Systemic $\beta_{2}$ responses were measured as plasma potassium levels, tremor, and heart rate taken at baseline and 30 minutes (all measurements made with the subject supine after nebulisation in the sitting position). Airway responses $\left(\mathrm{FEV}_{1}, \mathrm{FEF}_{25-75}\right)$ were measured at baseline and 30 minutes.

\section{MEASUREMENTS}

Finger tremor was measured with an accelerometer transducer (Entran, Ealing, UK), ${ }^{11}$ heart rate was measured from standard lead II of an electrocardiogram monitor, and plasma potassium levels were assayed by flame photometry using an IL943 analyser (Instrumentation Laboratory Ltd, Warrington, UK). The intraassay and interassay values for analytical imprecision were $0.41 \%$ and $1.04 \%$, respectively.

Plasma salbutamol levels were assayed by high performance liquid chromatography (HPLC), the extraction process using silica adsorption with chromatography followed by reverse phase ion pair HPLC and electrochemical detection. The analytical imprecision for plasma salbutamol was $7.8 \%$ (intra-assay) and $6.7 \%$ (interassay). The HPLC detection limit for salbutamol was $0.02 \mathrm{ng} / \mathrm{ml}$.

\section{STATISTICAL ANALYSIS}

The results were analysed using the Statgraphics statistical software package (STSC Software Publishing Group, Rockville, USA). Data for tremor were log transformed as it was not normally distributed. Salbutamol levels were calculated as maximal (Cmax) and average (Cav) over 0-30 minutes. For all parameters comparisons were made by analysis of variance and Bonferroni's multiple range testing (set at 95\% confidence limits) was used to establish where the differences between groups were significant. A probability value of $p<0.05$ (two-tailed) was considered as being of significance.

Table 2 Mean (SE) baseline values for pharmacodynamic parameters

\begin{tabular}{lccc}
\hline & Normals & Mild asthma & Severe asthma \\
\hline $\mathrm{FEV}_{1}(\mathrm{l})$ & $5.02(0.14)$ & $3.81(0.26)$ & $1.42(0.13)$ \\
$\mathrm{FEF}_{25-75}(1 / \mathrm{s})$ & $5.29(0.24)$ & $3.59(0.27)$ & $0.83(0.12)$ \\
$\mathrm{Log}_{\text {tremor }}\left(\mathrm{mg}^{2} / \mathrm{s}\right)$ & $2.39(0.15)$ & $2.33(0.12)$ & $2.48(0.11)$ \\
Heart rate $(\mathrm{beats} / \mathrm{min})$ & $64.1(2.9)$ & $66.3(2.0)$ & $63.9(2.7)$ \\
Potassium $(\mathrm{mmol} / \mathrm{l})$ & $3.89(0.07)$ & $3.98(0.06)$ & $3.93(0.06)$ \\
\hline
\end{tabular}

Values are shown for airways and extrapulmonary parameters at baseline prior to administration of salbutamol. For $\mathrm{FEV}_{1}$ and $\mathrm{FEF}_{25-75}$ there were significant $(\mathrm{p}<0.05)$ differences between each of the three groups.

\section{Results}

PHARMACOKINETICS

There were significant differences in Cav over 0-30 minutes between the patients with severe asthma and both normal subjects or those with mild asthma. For Cmax there was a significant difference between normal subjects and those with severe asthma (table 1, fig 1). For both Cav and Cmax there were no differences between normal subjects and those with mild asthma.

\section{PHARMACODYNAMICS}

Airway $\beta_{2}$ adrenoceptor responses

Baseline values (pre-salbutamol) for airway parameters showed significant differences between each of the three groups (table 2). Responses (as change from baseline) after administration of salbutamol showed a significantly lower improvement in $\mathrm{FEF}_{25-75}$ in the group with severe asthma compared with either the normal subjects or those with mild asthma (table 1, fig 2). For FEV 1 there were no differences in response between the three groups.

\section{Extrapulmonary $\beta_{2}$ adrenoceptor responses}

Pre-salbutamol baseline values for extrapulmonary $\beta_{2}$ adrenoceptor parameters were not significantly different between the three groups (table 2). After administration of salbutamol the group with severe asthma exhibited attenuated responses (as change from baseline) which were significantly different from those with mild asthma for tremor and from normal subjects for heart rate (table 1, fig 1). There were no differences between the three groups in potassium levels.
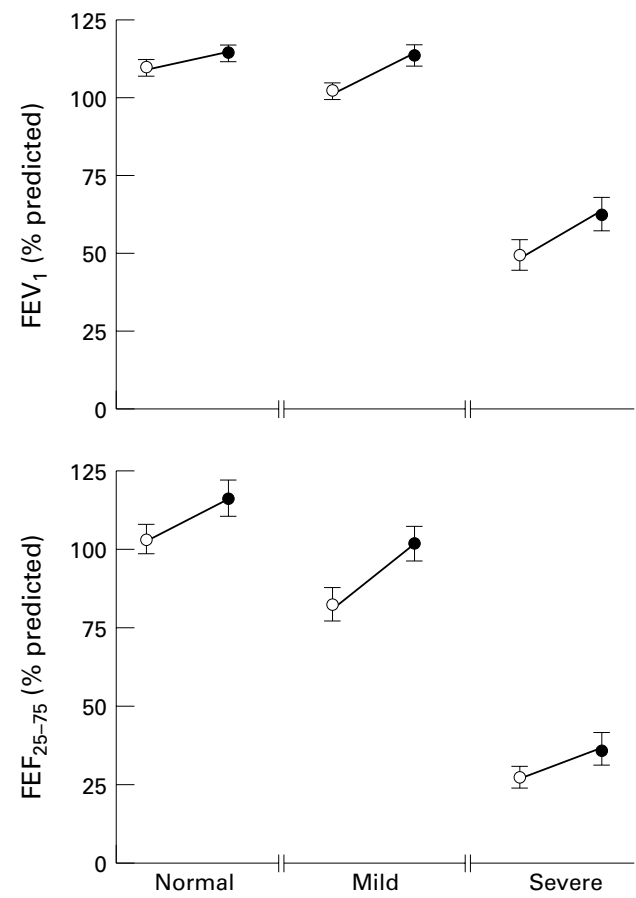

Figure 2 Mean (SE) baseline (O) and post-salbutamol (O) airway responses for $F E V_{1}$ and $\mathrm{FEF}_{25-75}$ as percentage predicted. 


\section{Discussion}

Our results have shown differences in the early lung absorption profile of salbutamol between patients with severe asthma compared with either normal subjects or those with mild asthma. This was mirrored by attenuated $\beta_{2}$ adrenoceptor responses for both airway $\left(\mathrm{FEF}_{25-75}\right)$ and systemic (tremor) parameters. The reason for the difference in $\mathrm{FEF}_{25-75}$ response but not $\mathrm{FEV}_{1}$ response may be explained by the fact that $\mathrm{FEF}_{25-75}$ is a more sensitive index of small airway calibre. It was interesting to note that there was no difference in the early lung salbutamol absorption profile between normal subjects and those with mild asthma in view of the difference in baseline $\mathrm{FEF}_{25-75}$ values. This may suggest that there is a threshold limit for $\mathrm{FEF}_{25-75}$ below which lung absorption begins to decline as a consequence of reduced peripheral lung delivery.

It is likely that the early pharmacokinetic profile of salbutamol represents absorption mainly from the peripheral alveolar rather than the proximal bronchial sites. Thus, in patients with severe asthma, reduced peripheral absorption of salbutamol may result in a lower systemic activity, which may translate into a more favourable therapeutic index when administering high doses to such patients. We tried to achieve optimal nebulised dose delivery using the breath assisted Ventstream which has been shown to deliver more salbutamol to the lung than a conventional jet nebuliser (Hudson Updraft II). ${ }^{12}$ Whether or not we would have found the same differences in lung bioavailability between the groups using a more efficient device such as a spacer is worthy of further investigation.

Radiolabelling studies have shown that reduced airway calibre may have a direct effect on the peripheral deposition of inhaled drugs. ${ }^{12}$ Zainudin et al in a radiolabelling study found that the bronchodilator response was determined by the total amount of drug delivered rather than its site of distribution. ${ }^{13}$ It is also possible that severely constricted airways may be less responsive than mildly constricted airways to the same delivered dose of $\beta_{2}$ agonist as a consequence of altered airways geometry.
We have shown in a previous study that the lung absorption profile for salbutamol is related to the bronchodilator response in terms of improved delivery when comparing two different nebulisers. ${ }^{12}$ It is therefore conceivable that the severity of peripheral airway constriction may significantly influence the acute bronchodilator response to $\beta_{2}$ agonists as in an episode of acute severe asthma. The reduced lung bioavailability of salbutamol in severe acute asthma could be overcome by either increasing the dose or improving drug delivery. The logical extension of the present study is to evaluate plasma salbutamol pharmacokinetic data in patients with acute asthma and to correlate severity of airflow obstruction, salbutamol bioavailability, and bronchodilator responses.

This study was supported by a university grant.

1 Melchor R, Biddiscome MF, Mak VHF, Short MD, Spiro SG. Lung deposition patterns of directly labelled salbutamol in normal subjects and in patients with reversible airflow obstructions. Thorax 1993;48:506-11.

2 Pavia D, Thomson ML, Clarke SW, Shannon HS. Effect of lung function and mode of inhalation on penetration of aerosol into the human lung. Thorax 1977;32:194-7.

3 Benson MK, Curry SH, Mills G, Hughes DT. Uptake of disodium cromoglycate in obstructive airways disease. Clin Allergy 1973;3:389-94.

4 Newnham DM, Wheeldon NM, Lipworth BJ, McDevitt DG. Single dosing comparison of the relative cardiac $\beta_{1} /$ $\beta_{2}$ activity of inhaled fenoterol and salbutamol in normal subjects. Thorax 1993;48:656-8.

5 Lipworth BJ, Newnham DM, Clark RA, Dhillon DP, Winter JH, McDevitt DG. Comparison of the relative airways and systemic potencies of inhaled fenoterol and salbutamol in asthmatic patients. Thorax 1995;50:54-61.

6 Lipworth BJ. Pharmacokinetics of inhaled drugs. Br f Clin Pharmacol 1996;42:697-705.

7 Clark DJ, Lipworth BJ. Effect of multiple actuations, delayed inhalation and antistatic treatment on the lung bioavailability of salbutamol via a spacer device. Thorax 1996 51:981-4.

8 Clark DJ, Gordon-Smith J, McPhate G, Clark G, Lipworth BJ. Lung bioavailability of generic and innovator salbutamol metered dose inhalers. Thorax 1996;51:325-6.

9 Clark DJ, Lipworth BJ. Lung bioavailability of chlorofluorocarbon free, dry powder and chlorofluorocarbon containing formulations of salbutamol. Br f Clin Pharmacol 1996;41:247-9.

10 Chrystyn H, Corlett SA, Silkstone V. Lung bioavailability of generic and innovator salbutamol MDIs. Thorax 1996; 51:658.

11 Lipworth BJ, McDevitt DG. Beta-adrenoceptor responses to inhaled salbutamol in normal subjects. Eur $\mathcal{F}$ Clin Pharmacol 1989;36:239-45.

12 Newnham DM, Lipworth BJ. Nebuliser performance, pharmacokinetics, airways and systemic effects of salbutamol given via a novel nebuliser delivery system (Ventstream). Thorax 1994;49:762-70

13 Zainudin B, Biddescombe M, Tolfree S, Short M, Spiro SG. Comparison of bronchodilator responses and deposition patterns of salbutamol from a pressurised metered dose inhaler, as a dry powder, and as a nebulised solution. Thorax 1990;45:469-73. 